\title{
PRODUCTO INTERNO BRUTO
}

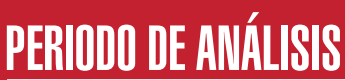

$2000 \mathrm{AL} 2013$

EI PIB representa el valor monetario de todos los bienes y servicios de consumo final (vivienda, comercio, servicios, gobierno, transporte, etc.) producidos por un país en un determinado período; normalmente ese período es anual.

EI PIB es un indicador que mide el nivel de bienestar de distintos países; mientras más elevado sea, mayor será su bienestar y viceversa.

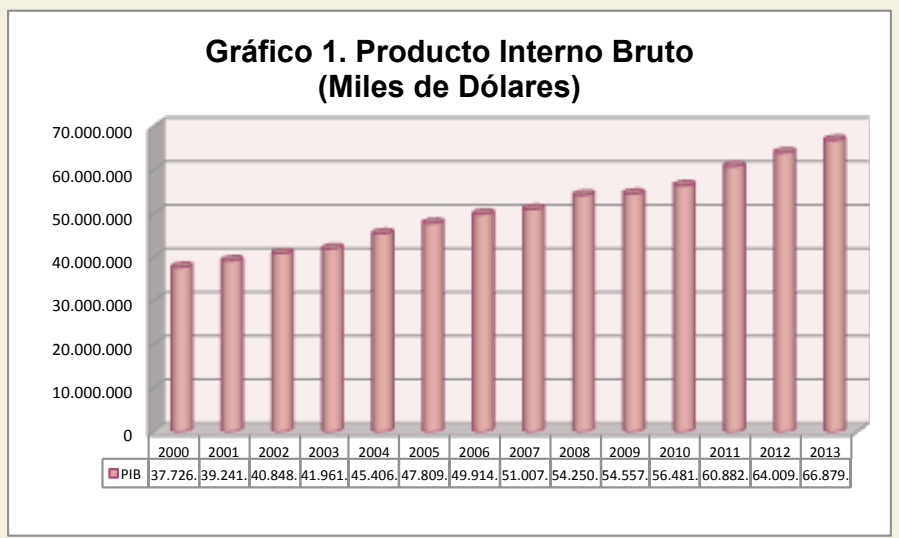

Fuente: Banco Central del Ecuador. Abril 2014

Elaboración: Personal Técnico Observatorio Económico y Social de Tungurahua

Desde el año 2000 hasta el 2010 la actividad económica del Ecuador registró tasas de crecimiento reales positivas, aunque muy variadas y dentro de este período en el 2004 presenta un incremento considerable; en el 2009 en cambio existe una caída debido a la crisis financiera internacional entre el 2007 y 2009 que ocasionó altas tasas de desempleo en Estados Unidos y Europa y por lo tanto la reducción de remesas provenientes de nuestros migrantes.
A partir del 2010 se mantiene la tendencia al alza mucho más sostenida, situación que el Banco Central del Ecuador lo atribuye al incremento significativo del valor agregado petrolero (VAP).

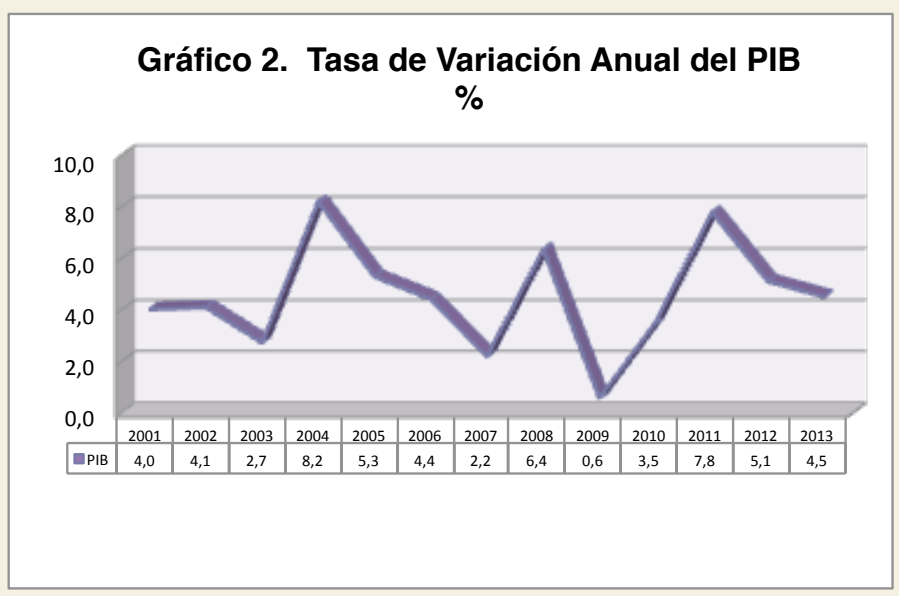

Fuente: Banco Central del Ecuador. Abril 2014

Elaboración: Personal Técnico Observatorio Económico y Social de Tungurahua

Durante estos años se destacan los crecimientos en el 2004 y 2011, tal como lo muestra la gráfica. Para el 2010 la actividad económica registra una tasa de $3.5 \%$, y un crecimiento continuo debido a una leve recuperación de las economías mundiales afectadas por la crisis financiera.

Para el cierre de 2011, se logra un crecimiento de $7.8 \%$, el más alto desde el 2004, debido al aumento de los ingresos petroleros y una excelente recaudación tributaria; al cierre del 2012, la tasa de crecimiento fue de $5.1 \%$, la misma que superaba las expectativas. Con respecto al 2013, el PIB tuvo un crecimiento anual de $4.5 \%$, de acuerdo a las cifras oficiales del BCE. 
Talle. 1 PRODUUTO IITERIU BRUTO POR IIDUSTRAA

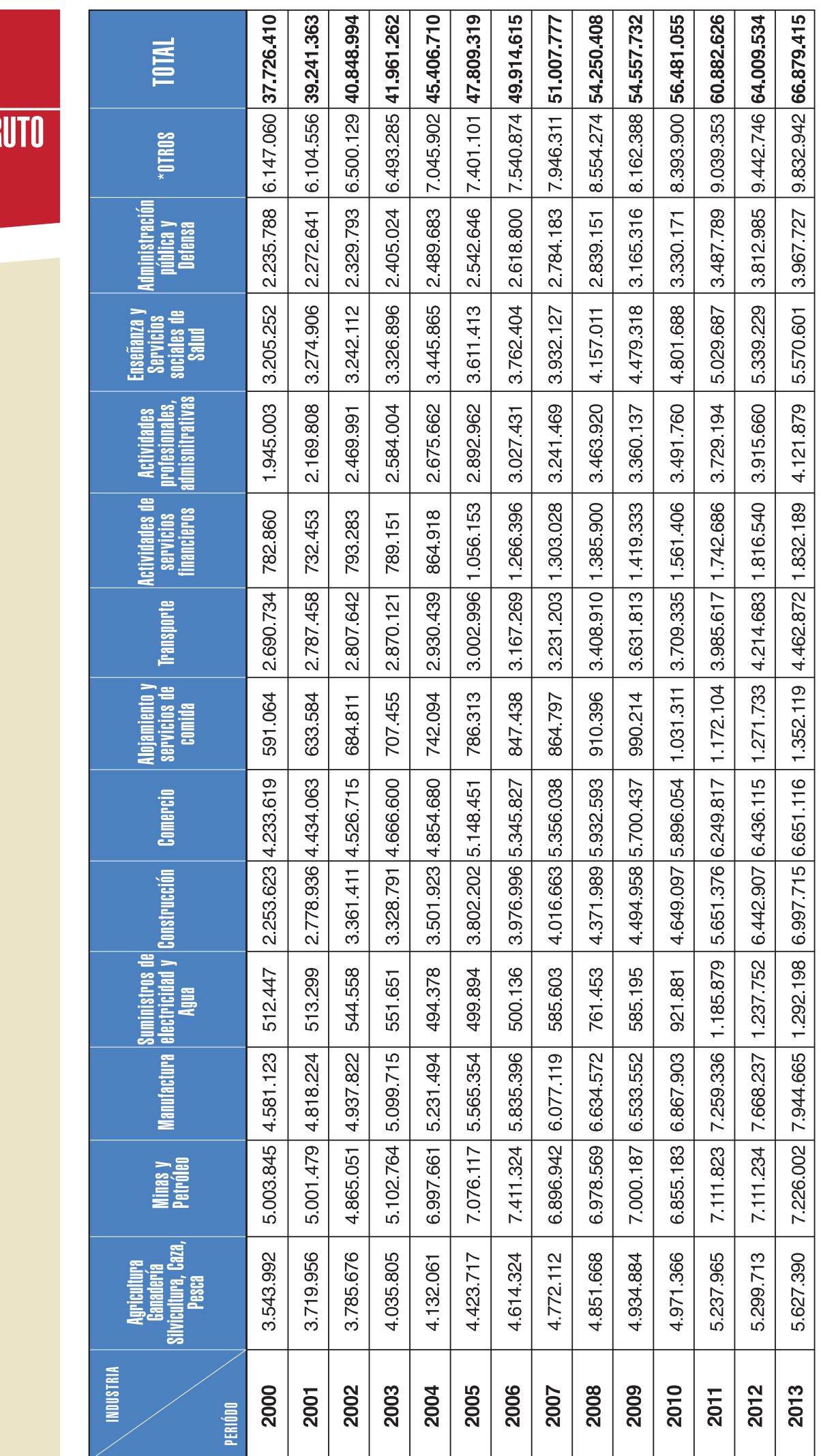

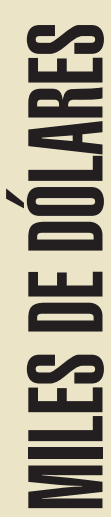




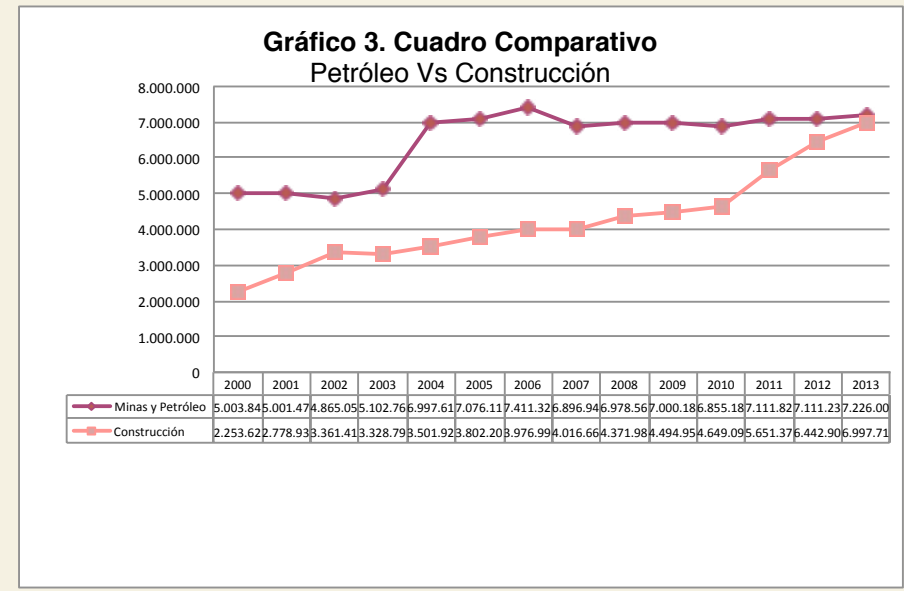

Fuente: Banco Central del Ecuador. Abril 2014

Elaboración: Personal Técnico Observatorio Económico y Social de Tungurahua

Durante estos años de dolarización el crudo ha sido el motor de la economía ecuatoriana y sus resultados se han sustentado en sus elevados precios. Pero la actividad no petrolera más significativa y un excelente indicador del bienestar económico lo constituyó la construcción que ha crecido en un $67,80 \%$ del 2000 al 2013, la gran demanda en este sector ha sido un gran incentivo para su auge y dinamismo, por efecto de las remesas de nuestros migrantes.

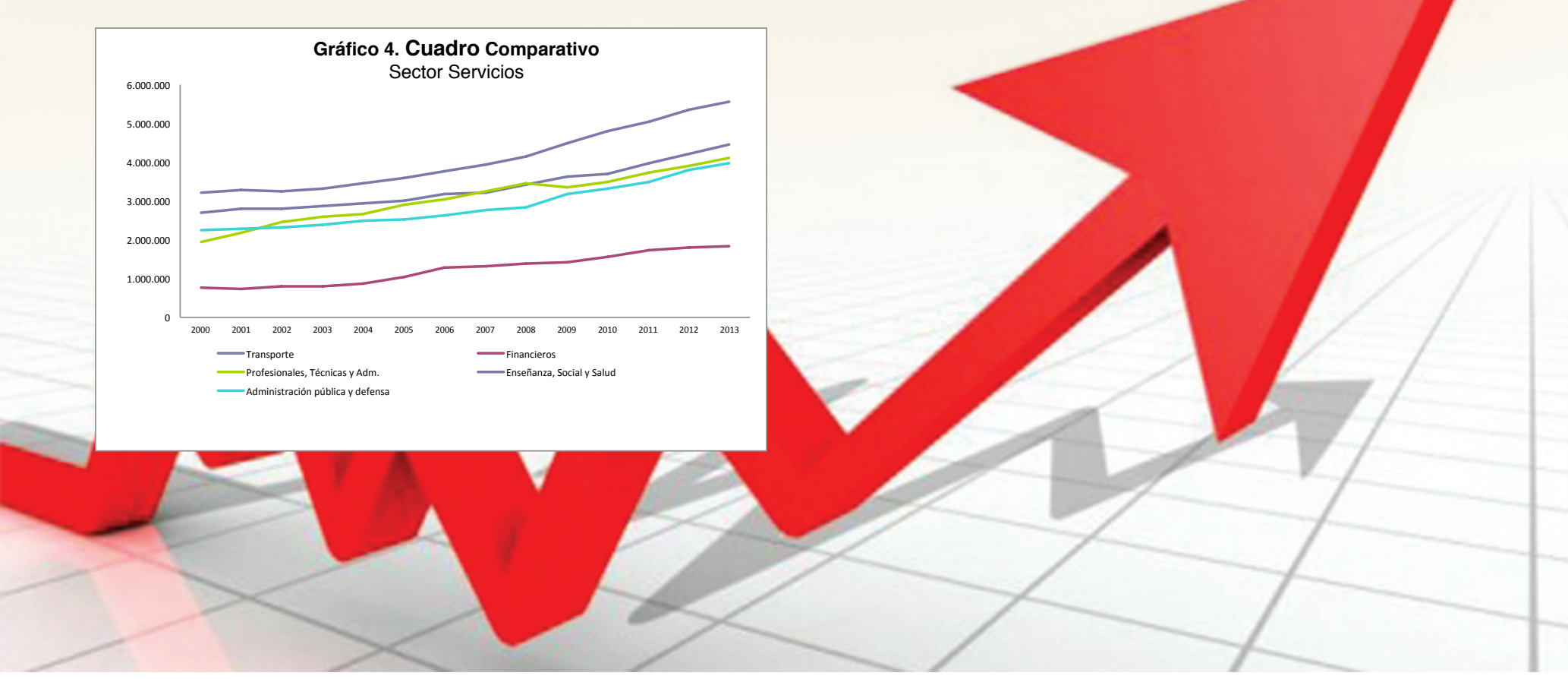

Este sector es muy importante porque concentra abundante fuerza laboral que da como resultado el crecimiento de la producción, consumo, inversión, producción, etc. Comprende todos los consumos de salud, educación, seguros, etc. En el Sector Servicios Financieros y de seguros, presentan un crecimiento notable, destacándose aún más en el 2011 con un crecimiento del $11,61 \%$ con relación al 2010, incidiendo en éste el peso financiero de Estados Unidos y Canadá. El resto de servicios presentan una tendencia más o menos creciente debido al incremento en los ingresos de las familias que hace que existe mayor demanda de servicios.

\section{Referencias}

- Banco Central de Ecuador, Información Estadística Mensual No.1946 Abril 2014. Producto Interno Bruto (En Línea) disponible en: http://contenido.bce.fin.ec/home1/estadisticas/bolmensual/IEMensual.jsp

\section{Observatorio Económico y Social de Tungurahua (OBEST) - Universidad Técnica de Ambato. Lic. Sandra Garcés}

